\title{
AGRESI ISRAEL TERHADAP PALESTINA PERSPEKTIF HUKUM HUMANITER INTERNASIONAL
}

\author{
Oleh: \\ Aryuni Yuliantiningsih \\ Fakultas Hukum Universitas Jenderal Soedirman Purwokerto
}

\begin{abstract}
Israel's agrresion to Palestina has international reactions because of enormous victims caused by that action, whom mostly were civilians. According humanitarian law, Israel's agression to Palestina had breached humanitarian law principles, there are : humanity principle, limitation principle and distinction principle. Israel has done war crimes so international society asked how Israel can be justiced? There are three mechanism to enforce humanitarian law. First, the contracting parties of Jeneva Convention State to enact any legislation neccessary to provide effective penal sanction for person committing or ordering to be comitted any of the grave breaches, second by ad hoc tribunal and third by International Criminal Court, but it is rather difficult to prosecute Israel because Israel don't ratificate Roma Statuta 1998.
\end{abstract}

Kata kunci : Agresi Israel, Palestina

\section{A. Pendahuluan}

Beberapa bulan terakhir ini (sejak tanggal 27 Desember 2008 - 20 Januari 2009), dunia internasional dikejutkan dengan adanya serangan melalui pemboman lewat udara maupun darat yang dilakukan oleh Israel terhadap Palestina di Jalur Gaza. Serangan ini sebenarnya ditujukan untuk melumpuhkan pejuang Hamas (Harakat al Muwaqawwamatul Islamiyah) atau secara harwiyah disebut Gerakan Perlawanan Islam agar menghentikan serangan roketnya ke Israel serta menghentikan suplai senjata HAMAS yang dikirim melalui terowongan-terowongan bawah tanah.

Hamas dicap sebagai organisasi teroris, oleh Israel, Amerika Serikat dan Uni Eropa. Namun oleh pendukungnya, organisasi itu dianggap sebagai kekuatan perjuangan yang sah untuk membela Palestina dari pendudukan brutal militer Yahudi.

Akibat dari serangan yang berlangsung selama 22 hari tersebut sekitar 1434 penduduk Palestina tewas menjadi korban. Korban penduduk sipil berjumlah 960, 239 polisi dan 235 pejuang Hamas. Dari 960 penduduk sipil yang tewas terdiri dari 288 anak, 121 wanita, dan 409 penduduk sipil selain wanita dan anakanak. Menurut data dari Departemen Kesehat- an Palestina, korban luka-luka mencapai 5303 yang terdiri dari 1606 anak-anak dan 828 Wanita. ${ }^{1}$ Sebagi-an besar penduduk sipil menjadi korban atas serangan yang membabi buta. Kerusakan rumah diderita oleh 6000 kepala keluarga yang mengalami rusak ringan dan 10.000 kepala keluarga mengalami rusak parah. Kerugian diperkirakan mencapai 2,2 milyar dollar AS. Di samping itu penduduk juga mengalami kesulitan untuk mengungsi dan menerima bantuan kemanusiaan karena adanya blokade di perbatasan Palestina dan Mesir. Serangan Israel juga telah menghancurkan rumah-rumah, masjid dan kantor lembaga bantuan PBB dan infra-struktur lain. ${ }^{2}$

Sebagian besar negara di berbagai belahan dunia, terutama negara-negara yang sebagian besar penduduknya beragama islam mengutuk agresi Israel ke Palestina. Bahkan badan Hak Asasi Manusia di Israel sendiri mengecam tindakan tersebut. Para pembela hak-hak asasi manusia internasional dengan tegas me-nyatakan bahwa agresi ini merupakan kejahatan perang. Selain itu Israel dalam

\footnotetext{
Data Korban Invasi Gaza tersedia di http:// www. Dakwatuna.com diakses tanggal 28 Maret 2009.

2 Kerusakan Akibat Agresi Israel http:// www.eramuslim. Com, diakses 31 Januari 2009
} 
serangannya ke Palestina juga telah mengakui menggunakan senjata kimia yaitu bom fosfor putih yang sebenarnya telah ada pelarangan menggunakan sen-jata tersebut karena akan merugikan penduduk sipil. Hal ini terlihat dari bangunan yang hancur dan luka bakar yang sangat parah dari para korban. ${ }^{3}$

Atas situasi tersebut, negara-negara yang tergabung dalam Liga Arab segera mengadakan pertemuan untuk membahas tindakan apa yang harus segera ditempuh untuk menyelesaiakan konflik. Perserikatan Bangsa-Bangsa telah mengeluarkan Resolusi No 1860/2009 agar para pihak yang berperang segera mengadakan gencatan senjata, namun para pihak tidak menghiraukan resolusi tersebut. PBB juga telah mengakui bahwa blokade Israel terhadap Gaza merupakan kejahatan perang. Organisasi Konferensi Islam juga menuntut penyelidikan atas kejahatan perang Israel. ${ }^{4}$ Masyarakat internasional bertanya-tanya mengapa PBB sebagai organisasi inter-nasional yang berwenang untuk menyelesaikan masalah yang mengganggu perdamaian dan keamanan internasional tidak dapat segera bertindak.

Berdasarkan uraian di atas, maka tulisan ini dibuat untuk menjelaskan permasalahan tentang pelanggaran prinsip-prinsip hukum humaniter dalam agresi Israel ke Palestina dan mekanisme penegakan hukum humaniter bagi pen-jahat perang Israel.

\section{B. Pembahasan}

\section{Sejarah konflik Israel-Palestina}

Sebelum masuk ke pembahasan mengenai agresi Israel ke Palestina perlu kiranya di ketahui terlebih dahulu mengapa konflik antara Israel dan Palestina sampai sekarang terus berlanjut dan berkepanjangan. Hal ini dapat dilihat dari perspektif teologis dan historis. Persoalan Palestina mencuat menjadi isu internasional sejak berakhirnya Perang Dunia Pertama sebagai akibat runtuhnya Ottoman Empire Turkey. Palestina akhirnya berada di

\footnotetext{
3 Israel Akui gunakan Bom fosfor Putih, tersedia di http://www. eramuslim.com, diakses tanggal 11 April 2009

4 PBB Akui Blokade Sebagai Kejahatan Perang, www. Antara. co.id. diakses 28 Maret 2009
}

antara negara-negara Arab eks Ottoman Turkey yang berada di bawah administrasi Inggris. Hal ini berdasarkan mandat dari Liga BangsaBangsa. Sesungguhnya mandat ini di-adopsi dari Deklarasi Balfour tahun 1917 yang isinya menyuarakan dukungan untuk pendirian suatu negara di tanah air Palestina untuk orang Yahudi. Berangkat dari semangat Deklarasi Balfour komunitas Yahudi yang menyebar di seluruh dunia bertekad untuk mendirikan negara di tanah yang dijanjikan Tuhan mereka.

Secara teologis, zionis menganggap Palestina sebagai tanah mereka dalam Perjanjian lama yang dinyatakan kawasan itu sebagai 'tanah yang dijanjikan tuhan' (promised land) untuk bangsa Israel, sebaliknya secara historis, rakyat Palestina menyatakan kami bangsa Palestina berada di negeri ini sejak jaman Umar bin khatab. ${ }^{5}$

Sekitar 100.000 orang berpindah ke Palestina antara 1920-1929, ketika waktu itu ada 750.000 orang penduduk Palestina. Di samping itu peristiwa haloucoust pembantaian Yahudi oleh NAZI membuat semua komunitas Yahudi lari dari daratan Eropa. Zionis memegang kendali penuh atas perpindahan ini. Orang-orang Yahudi yang menginjakkan kaki di palestina ditemui oleh kelompok Zionis yang menentukan di mana mereka akan tinggal dan pekerjaan apa yang akan didapatkan.

Pendudukan yang diterapkan Israel pada tahun 1948 dengan jalan mengusir orang-orang Arab dari Palestina. Setiap desa atau pemukiman Arab yang tidak menyerah kepada kekuatan Yahudi akan dihancurkan dan orang-orangnya diusir. Dengan cara ini 400 desa Palestina terhapus dari peta selama 1948-1949. Hak milik yang ditinggalkan orang-orang Palestina dikuasai orang-orang Yahudi atas dasar hukum hak milik tak di-tempati. Organisasi zionis meng-gunakan tekanan dan kekuatan untuk mengusir orang-orang Palestina dari tanahnya yang telah mereka tempati selama berabadabad, sehingga sekarang orang-orang Palestina hanya diberi tempat di Jalur Gaza.

\footnotetext{
5 Unahar Ilyas, Arab Harus Bersatu Hadapi Israel, Suara Merdeka, 11 Januari 2009.
} 
Sejak saat itu muncullah beberapa kali peperangan Yahudi dan Palestina. Sejak dulu sebenarnya sudah ada pe-rundingan tetapi selalu dilanggar oleh Israel. Di Palestina sendiri mencatat munculnya Yasser Arafat dan PLO, serta Fatah. Perundingan-perundingan dilakukan sampai muncul perundingan Oslo yang menjanjikan kemerdekaan bagi Palestina namun lagi-lagi Israel tidak menepati janji. Karena selalu tak ditepati, rakyat palestina melawan dengan intifadah (melempar batu). Hal ini dihentikan dengan perjanjian, tetapi dilanggar lagi, begitu seterusnya.

Para pejuang intifadah ini bergabung dalam Hamas (Harakat al Muwa-qawwamatul Islamiyah atau Gerakan Perlawanan Islam). Melihat perjanjian selalu tidak ada gunanya dan resolusi PBB tidak bisa dijalankan atau jika dilanggar oleh Israel tidak muncul sanksi maka Hamas bertekad merebut Palestina dengan berperang, meskipun hanya dengan menggunakan batu.

Di Palestina ada faksi yang eksis yaitu Hamas dan Fatah. Pada saat terjadi perbedaan pendapat antara Fatah dan Hamas, ketika Yassir Arafat masih hidup, perbedaan tidak sampai menimbulkan sengketa karena Hamas menghormati pemimpin Palestine Liberation Organiza-tion (PLO) itu. Namun begitu Arafat meninggal dan diganti oleh Mahmod Abbas sengketa tak terdamaikan, bahkan Abbas dikudeta di daerah Gaza. Gaza kemudian dibagi menjadi dua yaitu Tepi Barat (Fatah) dan Jalur Gaza (Hamas).

Sebenarnya sebelum terbagi menjadi dua ada pemilu demokratis yang dimenangkan oleh Hamas. Sayang Amerika, Eropa dan sekutu tak mengakui bahkan Hamas diboikot dengan tujuan agar rakyat menderita dan meminta Abbas memimpin. Akan tetapi rakyat Palestina pro Hamas bersedia menderita karena melihat Hamas lebih tulus dan islami dibanding dengan fatah yang sekuler. Sekarang Israel bertujuan menghancurkan Hamas dan ingin mendudukkan fatah. Dalam protokoler Israel hanya ada dua cara untuk menghadapi musuh: didominasi dan dihancurkan. Fatah cen-derung bisa didominasi, sedang Hamas hanya hilang jika dihancurkan. ${ }^{6}$

\section{Tinjauan Umum tentang Hukum Humaniter}

Perang sebagai salah satu penyelesaian sengketa secara paksa seharusnya dihindari oleh negara-negara yang ber-sengketa untuk menyelesaikan konflik. Hal ini tercantum dalam Pasal 2 ayat 4 Prinsip PBB yang menentukan: all member shall refrain in their international relations from the trest or use of force againts the territorial integrity or political independence of any state ao any other manner inconsistence with the purpose of the United Nations. Seandainya perang harus ditempuh maka para pihak harus melaksanakan sesuai dengan hukum humaniter. Istilah hukum humaniter berawal dari istilah hukum perang (law of war), yang kemudian menjadi hukum sengketa bersenjata (law of armed conflict) dan sekarang dikenal sebagai hukum humaniter internasioonal (international humanitarian law). ${ }^{7}$

Dari sudut pandang hukum humaniter, perang merupakan suatu kenyataan yang tidak dapat dihindari sehingga hukum humaniter mencoba untuk mengatur agar suatu perang dapat dilakukan dengan memperhatikan prinsip-prinsip kemanusiaan atau memanusiawikan perang. ${ }^{8}$ Tujuan utama hukum humaniter adalah memberikan perlindungan dan pertolongan kepada mereka yang menderita/ menjadi korban perang, baik mereka yang secara aktif turut serta dalam permusuhan maupun yang tidak turut serta dalam permusuhan. ${ }^{9}$

Sumber utama hukum humaniter terdiri dari Hukum Den Haag dan Hukum Jenewa. Hukum Den Haag terdiri dari, Konvensi den Haag 1899 dan 1907 mengenai cara dan alat berperang. Konvensi Den Haag 1899 terdiri dari 3 konvensi dan tiga deklarasi, antara lain Konvensi II tentang Hukum dan kebiasaan Perang di

\footnotetext{
Ibid.

Arlina Permanasari dkk, 1999, Pengantar Hukum Humaniter, Jakarta: ICRC, hlm.1

8 Ibid. hlm. 12

9 Haryomataram, 2005, Pengantar Hukum Humaniter, Jakarta: PT Rajawali Press, hlm. 3
} 
Darat serta adanya deklarasi larangan penggunaan proyektil-proyektil yang menyebabkan gas-gas cekik dan beracun dilarang. Sedangkan Konvensi Den Haag 1907 terdiri dari 13 Konvensi, konvensi yang penting antara lain Konvensi III tentang Cara Memulai Permusuhan dan Konvensi IV tentang Hukum dan Kebiasaan Perang di Darat. Konvensi IV ini sering disebut dengan Hague Regulation (HR). HR memberikan batasan yang lebih tegas terhadap pemakaian alat dan metode perang. Di samping itu di dalam terdapat Martens Clause, dimana dalam Martens Clause dinyatakan bahwa dalam keadaan apapun harus diperhatikan perlakuan kemanusiaan.

Hukum Jenewa yang mengatur mengenai perlindungan korban perang terdiri dari empat perjanjian pokok, yaitu:

a. Konvensi Jenewa I tentang Perbaikan keadaan tentara yang luka dan sakit di medan pertempuran darat.

b. Konvensi Jenewa II tentang Perbaikan keadaan Tentara yang luka dan Sakit di Medan Pertempuran laut

c. Konvensi Jenewa III tentang Perlakuan Tawanan Perang

d. Konvensi Jenewa IV tentang Perlindungan Penduduk Sipil di Waktu Perang.

Setelah Perang Dunia II, dunia ditandai dengan proses dekolonisasi, sehingga banyak peperangan tidak lagi bersifat internasional, namun tidak sedikit korban akibat konflik bersenjata non internasional ini. Masyarakat internasional sepakat untuk mengatue masalah-masalah baru tersebut dan dibentuk-lah Protokol Tambahan Konvensi Jenewa tahun 1977 yang dikenal dengan protokol tambahan I dan Protokol Tambahan II tahun 1977

Selain sumber-sumber utama hukum humaniter terdapat sumber-sumber lain hukum humaniter yang mengatur alat dan metode berperang. Masyarakat internasional selalau berusaha untuk mengurangi penderitaann yang berlebihan yang ditimbulkan oleh perang. Beberapa perjanjian yang telah di-sepakati antara lain :

\section{a. The biological weapons Convention 1972}

b. The United Nations Convention on Conventional Weapons and the Protocols 1980,

c. The chemical Weapons 1993

d. Convention on Prohibitions or restrictions on the Use certain Conventional Weapons Which May be Deemed to Excessively injuries or to Have Indiscriminate Effects

Di samping peraturan-peraturan tersebut di atas, di dalam hukum humaniter dikenal asas-asas hukum hu-maniter yang juga harus diperhatikan pada saat mengadakan perang. Asas-asas utama dalam hukum humaniter tersebut terdiri dari : ${ }^{10}$

a. Asas kepentingan militer (military necessity), artinya para pihak yang bersengketa dibenarkan menggunakan kekerasan untuk menundukkan lawan demi tercapainya tujuan dan keberhasilan perang.

b. Asas perikemanusiaan (humanity)

Berdasarkan asas ini maka pihak yang bersengketa diharuskan untuk memperhatikan perikemanusiaan, dimana mereka dilarang menggunakan kekerasan yang dapat menimbulkan luka yang berlebihan dan penderitaan yang tidak perlu.

c. Asas kesatriaan (chivalry)

Asas ini mengandung arti bahwa di dalam perang, kejujuran harus diutamakan. Penggunaan alat-alat yang tidak terhormat, berbagai macam tipu muslihat dan cara-cara yang bersifat khianat dilarang.

Selain ada tiga asas utama hukum humaniter, terdapat pula prinsip-prinsip hukum humaniter yang harus diperhatikan dalam melakukan perang. Prinsip-prinsip tersebut adalah:

a. Prinsip pembedaan (distinction principle)

Prinsip pembedaan ini membedakan antara kombatan dan penduduk sipil dalam wilayah negara yang sedang berperang. Kombatan adalah penduduk yang secara aktif turut serta dalam permusuhan dan boleh dijadikan sasaran perang, sedangkan penduduk sipil adalah pen-duduk yang tidak ikut aktif dalam perang sehingga tidak boleh dijadikan sasaran perang. ${ }^{11}$

\footnotetext{
${ }^{10}$ Arlina Permanasari, op.cit., hlm. 11

${ }^{11} \mathrm{Ibid}, \mathrm{hlm} .73$
} 
Prinsip pembedaan ini dijabar-kan sebagai berikut $:^{12}$

1) Pihak yang bersengketa, setiap saat harus membedakan antara kombatan dan penduduk sipil un-tuk mlindungi objekobjek sipil

2) Penduduk sipil, demikian pula penduduk sipil secara perorangan tidak boleh di jadikan objek se-rangan

3) Dilarang melakukan tindakan kekerasan atau ancaman kekerasan yang tujuannya untuk menyebarkan teror terhadap penduduk sipil

4) Pihak yang bersengketa harus mengambil langkah pencegahan yang memungkinkan untuk menyelamatkan penduduk sipil atau setidak-tidaknya untuk menekan kerugian atau kerugian yang tidak disengaja sekecil mungkin

5) Hanya angkatan bersenjata yang berhak menehan dan menyerang musuh

6) Objek-objek sipil yang harus dilindungi antara lain, tempat ibadah, rumah sakit, sekolah, dan fasilitas-fasilitas publik.

b. Prinsip proporsionalitas

Para pihak dalam peperangan harus memperhatikan prinsip proporsionalitas atau keseimbangan. Prinsip ini bertujuan untuk menyeimbangkan antara kepentingan militer dan resiko yang akan merugi-kan penduduk sipil.

Dalam peperangan ternyata penduduk sipil sangat beresiko untuk menanggung akibat serangan militer. Sebagai contoh dalam Perang Dunia II pengeboman Hiroshima dan Nagasaki oleh tentara sekutu dalam usaha menaklukan Jepang. Sekutu berhasil dan Jepang menyerah. Dilihat dari segi kepentinagn militer Sekutu berhasil dengan menyerahnya Jepang, namun terdapat ribuan penduduk sipil yang meninggal akibat bom tersebut. Akibat pemboman itu ternyata tidak hanya menyebabkan matinya ribuan orang, tetapi ternyata masih menyisakan penderitaan yang berkepanjangan bagi penduduk Hiroshima dan Nagasaki.

12 Ibid, hlm. 74
Banyaknya bayi yang cacat karena radiasi, trau-ma yang ditinggalkan dan banyaknya gangguan fungsi reproduksi. ${ }^{13}$

c. Prinsip pembatasan (limitation)

Prinsip pembatasan ini berkaitan dengan tiga hal, yaitu ${ }^{14}$ :

1) Pembatasan sasaran lawan, artinya hanya lawan yang dapat diserang dengan mengupayakan kekerasan minimal

2) Pembatasan sasaran wilayah, adanya larangan menghancurkan tempat ibadah, peninggalan kebudayaan, ilmu pengetahuan dan wilayah yang tak dipertahankan, rumah sakit, pasar dan lain-lain.

3) Prinsip pembatasan sasaran keadaan, tindakan perang dilarang melakukan pengkhianantan da-lam arti tindakan purapura/menjebak lawan dan memberi cedera yang berlebihan.

\section{Pelanggaran Prinsip-prinsip Hukum Huma- niter dalam Agresi Israel Ke Palestina}

Dengan mengetahui prinsip-prinsip dalam hukum humaniter dan prinsip yang terkandung dalam Piagam PBB, jelas bahwa agresi Israel telah melanggar prinsip-prinsip dalam hukum humaniter. Agresi Israel ke Palestina selama 22 hari telah mengakibatkan korban penduduk sipil sekitar 1443 orang tewas dan 5000 orang lukaluka. Hal ini bertentangan dengan prinsip kemanusiaan. Prinsip kemanusiaan dan perlindungan terhadap penduduk sipil telah lama dikenal dalam membatasi korban karena peperangan. Alasan yang mendorong untuk diadakan pembatasan dalam perang, yaitu: ${ }^{15}$

a. adanya kenyataan bahwa kerugian yang di timbulkan oleh perang terhadap kemanusiaan menuntut diadakan pembatasan dalam melaksanakan perang

b. Kekejaman yang dilakukan karena perang terhadap manusia adalah bertentangan

\footnotetext{
${ }^{13}$ Sri Setianingsih Suwardi, 'Serangan Israel ke Libanon dikaitkan dengan Prinsip-Prinsip Hukum Humaniter', Jurnal HI Jakarta: UI, Vol 4 No 1 Oktober 2006, hlm.11

${ }^{14}$ Masyhur Efendi, 2005, Perkembangan Dimensi Hak Asasi Manusia (HAM) dan Proses Penyusunan Hukum Hak asasi Manusia (HAKHAM), Jakarta: Ghalia Indonesia, hlm. 197

${ }^{15}$ Sugeng Istanto, 1992, Perlindungan Penduduk Sipil Dalam Perlawanan Rakyat Semesta dan Hukum Internasional, Yogyakarta: Penerbit Andi Offset, hlm. 17
} 
dengan peradaban manusia yang menuntut diadakan pembatasan perang sesuai dengan martabat manusia

c. Adanya pengaruh faham perikemanusiaan dalam perang

Dalam Protokol Tambahan (selanjutnya disingkat PT) I Tahun 1977 Bab IV mengatur tentang Penduduk Sipil. Pasal 50 PT I tahun 1977 ini secara tegas membedakan orang-orang sipil dan pen-duduk sipil. Pasal 48 menentukan: pihak-pihak dalam sengketa harus membedakan antara penduduk sipil dan kombatan dan antara objek sipil dan sasaran militer, dan karenanya harus mengarahkan operasinya hanya terhadap sasaran militer saja.

Pasal 53 menentukan perlindungan bagi objek-objek budaya dan tempat pemujaan. Perlindungan terhadap objek-objek yang di perlukan untuk kelangsungan hidup penduduk sipil diatur dalam Pasal 54. Pihak yang bersengketa dilarang menimbulkan kelaparan sampai mati pada orang-orang sipil sebagai suatu cara berperang. Pasal 56 menentukan perlindungan terhadap bendungan, tanggul, pusat pembangkit tenaga listrik tidak boleh dijadikan sasaran perang.

Israel juga telah melanggar prinsip pembedaan, dimana dalam serangannya tidak membedakan antara penduduk sipil dan kombatan serta antara objek-objek militer dan objekobjek sipil yang tidak boleh dijadikan sasaran serangan militer. Sebagian besar korban yang tewas adalah penduduk sipil yang mencapai jumlah 960 jiwa. Selain itu Israel telah menghancurkan objek-objek sipil antara lain, rumah penduduk sipil, rumah sakit, sekolahsekolah, gedung PBB, instalasi listrik dan air, bahkan tempat ibadah.

Berkaitan dengan pelanggaran prinsip perikemanusiaan yang lain yaitu adanya larangan untuk menimbulkan luka yang berlebihan. Israel telah menggunakan bom fosfor putih yang menimbulkan luka yang berlebihan bagi penduduk sipil. Bom fosfor putih mengakibatkan luka bakar yang parah sampai menembus tulang manusia. Bom fosfor putih merupakan senjata yang telah dilarang digunakan dalam perang.

\section{Mekanisme Penegakan Hukum Humaniter}

Reaksi masyarakat internasional terhadap agresi Israel ke Palestina cukup keras. Masyarakat internasional telah menuduh Israel melakukan kejahatan perang dan ingin menuntut Israel untuk dapat diadili ke Mahkamah internasional. Tim Pencari Fakta PBB telah menyelidiki dan terbukti bahwa Israel memang telah melakukan kejahatan perang. Permasalahannya apakah mungkin Israel dapat diadili?

Jika terjadi pelanggaran terhadap hukum humaniter ada tiga alternatif mekanisme penegakan yang dapat ditempuh, untuk menghukum para pelaku kejahatan perang, yaitu ${ }^{16}$ :

a. Menurut Konvensi Jenewa 1949 dan Protokol Tambahan 1977

Berdasarkan pasal 49 ayat 1 Konvensi Jenewa 1949 maka Negara yang telah meratifikasi Konvensi Jenewa harus menerbitkan undang-undang nasional yang dapat memberi sanksi pidana yang efektif kepada setiap orang yang melakukan atau memerintahkan untuk melakukan pelanggaran berat terhadap Konvensi.

b. Melalui Mahkamah ad hoc kejahatan perang Dalam sejarah dikenal ada dua Mahkamah yang mengadili penjahat Perang Dunia II yaitu, Mahkamah Tokyo untuk mengadili para penjahat perang Jepang, mahkamah Nuremberg untuk mengadili penjahat perang Nazi, Jerman. Setelah Perang Dunia II, telah dibentuk Mahkamah Kriminal Internasional untuk bekas Yugoslavia (international crimi-nal Tribunal for the Former Yugoslavia/ICTY) dan untuk Rwanda (International Criminal Tribunal for Rwanda).

c. Melalui Mahkamah Pidana Inter-nasional (International Criminal Court/ICC)

ICC didirikan dengan Statuta Roma 1998. Mahkamah ini bersifat permanen untuk mengadili kejahatan-kejahatan yang sangat serius (the most serious crimes). ICC berwenang mengadili atas empat macam kejahatan, yaitu: genocide, Crimes againts humanity, Crimes of War dan Crimes of ag-

${ }^{16}$ Arlina Permanasari, op.cit., hlm. 181 
ression. ${ }^{17}$ ICC ini bersifat sebagai pelengkap dari pengadilan nasional, artinya jika suatu negara tidak mau (unwilling) atau tidak mampu (unable) mengadili pelaku kejahatan perang maka ICC baru dapat melaksanakan jurisdiksinya.

Negara-negara anggota PBB tidak secara otomatis terikat oleh Jurisdiksi ICC, tetapi melalui suatu pernyataan untuk mengikatkan diri dan menjadi pihak pada Statuta Roma. ICC mulai berlaku secara efektif sejak tahun 2002 ketika sudah mencapai 60 negara yang meratifi-kasi. ${ }^{18}$ Sampai saat ini Amerika Serikat dan Israel belum meratifikasi Statuta Roma 1998.

Dari ketiga mekanisme penegakan hukum humaniter tersebut di atas dapat dianalisis satu-persatu kemungkinan untuk mengadili Israel atas kejahatan perang yang sudah dilakukan. Melalui mekanisme pertama yang menyebutkan bahwa negara peratifikasi Konvensi Jenewa 1949 dan Protokol Tambahan 1977 harus menerbitkan undang-undang nasional yang memberi sanksi pidana efektif bagi pelaku kejahatan sulit di-tempuh karena sampai saat ini Israel belum meratifikasi Konvensi Jenewa 1949 dan tidak mungkin akan menghukum pe-laku kejahatan menurut hukum nasional-nya karena Israel ingin melindungi pelaku kejahatan yang dilakukan oleh warga negaranya sendiri.

Melalui mahkamah ad hoc yang khusus mengadili kejahatan Israel di Palestina di mungkinkan jika Dewan keamanan PBB mengeluarkan resolusi untuk membentuk mahkamah ini seperti dalam pembentukan ICTY dan ICTR. Dewan Keamanan PBB sebagai pemegang tanggung jawab utama dalam pemeliharaan perdamaian dan keamanan internasional dapat menentukan situasi adanya ancaman perdamaian, pelanggaran perdamaian dan tindakan agresi. Masyarakat internasional dapat terus mendesak Dewan Keamanan PBB untuk membentuk pengadilan kejahatan perang Israel.

\footnotetext{
${ }^{17}$ Arie Siswanto, 2005, Yurisdiksi material mahkamah Pidana Internasional, Jakarta: Ghalia Indonesia, hlm. 45

${ }^{18}$ Boer Mauna, 2005, Hukum Internasional, Pengertian, Peranan dan fungsi Dalam Era Dinamika Global, Bandung: Alumni, hlm. 263
}

Namun kendalanya, resolusi ini harus didukung dengan suara bulat dari lima anggota tetap Dewan Keamanan PBB yaitu, Amerika Serikat, Rusia, Inggris, Perancis, dan Republik Rakyat Cina. Dapat diperkirakan resolusi akan mendapat veto dari Amerika Serikat yang selalu memihak kapada Israel.

Kejahatan perang yang dilakukan oleh Israel sebenarnya termasuk salah satu kewenangan Mahkamah Pidana Internasional atau ICC sebagai pengadilan tetap yang mulai berlaku efektif sejak tahun 2002. Namun kewenangan ICC ini hanya berlaku bagi negara yang telah meratifikasi Statuta Roma 1998, sedang-kan Israel belum meratifikasi Statuta Roma 1998.

\section{C.Penutup}

1. Simpulan

a. Agresi Israel ke Palestina telah melanggar hukum humaniter internasional yang mengatur mengenai tata dan cara berperang serta perlindungan penduduk sipil dalam sengketa bersenjata. Israel telah melakukan serangan membabi buta yang bertentangan dengan prinsip kemanusiaan, prinsip pembatasan dan prinsip pembedaan sehingga dapat di katakan bahwa Israel melakukan kejahatan perang,

b. Masyarakat internasional masih kesulitan untuk mengadili Israel atas kejahatan yang dilakukan karena Israel belum meratifikasi Statuta Roma 1998.

\section{Saran}

Untuk menghukum negara yang melakukan kejahatan perang seperti Israel, masyarakat internasional dapat melakukan beberapa tindakan alternatif yaitu :

a. Pemutusan hubungan diplomatik dan hubungan lainnya dengan Israel.

b. Tindakan blokade yang dilakukan secara kolektif oleh negara-negara atau aktor-aktor internasional lainnya yang selama ini berhubungan baik secara langsung maupun tidak langsung dengan negara Israel.

c. Menerapkan prinsip jurisdiksi universal di mana setiap negara mempunyai kewenangan 
untuk mengadili setiap pelaku tindak pidana yang termasuk kejahatan serius tanpa memendang siapa pelakunya kapan dan dimana kejahatan dilakukan.

\section{Daftar Pustaka}

Efendi, Masyhur. 2005. Perkembangan Dimensi Hak Asasi Manusia (HAM) dan Proses Penyusunan Hukum Hak asasi Manusia (HAKHAM). Jakarta: Ghalia Indonesia;

Permanasari, Arlina, dkk. 1999. Pengantar Hukum Humaniter. Jakarta: ICRC;

Haryomataram. 2005. Pengantar Hukum Humaniter. Jakarta: PT Rajawali Press;

Istanto, Sugeng. 1992. Perlindungan Penduduk Sipil Dalam Perlawanan Rakyat Semesta dan Hukum Internasional. Yogyakarta: Penerbit Andi Offset;

Mauna, Boer. 2005. Hukum Internasional Pengertian Peranan dan Fungsi Dalam Era Dinamika Global. Bandung: Alumni;

Siswanto, Arie. 2005. Yurisdiksi Material Mahkamah Pidana Internasional. Jakarta: Ghalia Indonesia.

Yahya, Harun. 2005. Palestina, Zionisme dan Terorisme Israel. Bandung: PT Syamiil Cipta Media;

Suwardi, Sri Setianingsih. 'Serangan Israel ke Libanon Dikaitkan Dengan Prinsip-Prinsip Hukum Humaniter'. Jurnal HI, Vol. 4 No. 1 Oktober 2006.

\section{Sumber lain}

Konvensi Jenewa IV tahun 1949 tentang Perlindungan Penduduk Sipil;

Rome Statute of The Iternational Criminal Court, 1998;

http. www.eramuslim. com, diakses 31 januari 2009;

Unahar llyas, Arab Harus Bersatu Hadapi Israel, Suara Merdeka, 11 Januari 2009;

Ananonim, 'Data Korban Invasi Gaza, tersedia di htpp://www. dakwatuna.com diakses tanggal 28 Maret 2009;

Israel Akui gunakan Bom fosfor Putih, tersedia di http://www. eramuslim.com, diakses tanggal 11 April 2009;
Rudi Rizki, Beberapa Catatan Tentang Penegakan Hukum Humaniter dan hak Asasi Manusia, makalah tanpa tahun. 
118 Jurnal Dinamika Hukum

Vol. 9 No. 2 Mei 2009 